\title{
CFD Analysis of Torque and Power for Single Rotor, Dual Rotor, and Ducted Dual Rotor Wind Turbine
}

\author{
Vinay Mishra, H.K Paliwal
}

\begin{abstract}
With the present advancement, a wind turbine needs a wind rotor with high torque and power. The present study aims to enhance the torque and power of wind turbine by employing the ducted dual rotor. In this regard, CFD analysis is performed to analyze the torque and power produced for horizontal axis single rotor bare wind turbine, dual rotor wind turbine, and convergent-divergent ducted type dual rotor wind turbine. The comparative study is conducted to enhance the power and torque for the aforementioned rotor type. The results highlight the maximum value of torque for a dual ducted wind turbine is $36.9 \%$ more than a dual rotor at $16 \mathrm{~m} / \mathrm{s}$ of wind velocity and $92.2 \%$ more than a single rotor at $16 \mathrm{~m} / \mathrm{s}$ of wind velocity, and the maximum value of the power produced for a dual ducted wind turbine is $40.48 \%$ more than a dual rotor at $16 \mathrm{~m} / \mathrm{s}$ of wind velocity and $139.66 \%$ more than a single rotor at $16 \mathrm{~m} / \mathrm{s}$ of wind velocity. Therefore result suggested that a dual ducted wind turbine is better than a single rotor wind turbine.
\end{abstract}

Keywords: TSR- Tip Speed Ratio, BL- Braking Load, BT-Braking Torque, SP-Shaft Power.

\section{INTRODUCTION}

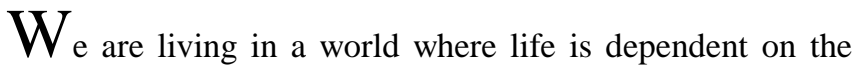
various resources in which some are conventional and some are non-conventional. Out of which conventional resources are having some disadvantages, these resources are not very harmful to the human being. Researchers have been going on non-conventional energy resources in which wind energy is one of them .lots of research have been going on in various non-conventional energy resources wind energy is one of them .for single and dual rotor number of research are going on. The maximum amount of power that can be extracted is only $59 \%$ which is known as the Betz limit. For single rotor[1] maximum power extracted is 23 \%but for dual rotor it was $33 \%$ which was about 43 \%higher when a higher segment was considered but besides shrouded wind turbine produces more power or can extract more power as compared to bare turbine

Manuscript received on April 20, 2021.

Revised Manuscript received on April 26, 2021.

Manuscript published on April 30, 2021.

*Correspondence Author

Mr. Vinay Mishra*, Research Scholar, Department of mechanical engineering, Dr. A.P.J. Abdul Kalam Technical University Lucknow, India, Email; vinaymishra1911@gmail.com

Dr. H.K. Paliwal, Professor, Department of mechanical engineering,(IET LKO) Dr. A.P.J. Abdul Kalam Technical University Lucknow, India. Email: hkpaliwal@yahoo.com

(C) The Authors. Published by Blue Eyes Intelligence Engineering and Sciences Publication (BEIESP). This is an open access article under the CC BY-NC-ND license (http://creativecommons.org/licenses/by-nc-nd/4.0/)
[6]. So taking dual rotor and shrouded or ducted dual rotor convergent-divergent in nature, CFD analysis is to be carried out. Wind turbine dimensions are considered for analysis as per [1].CATIA model was prepared to proceed for CFD analysis then graphs are plotted to obtain results.

\section{LITERATURE SURVEY}

In many research, it was observed that dual rotors extract more energy/power from the wind as compare to a single rotor wind turbine. Moreover, diffuser/ducted type wind turbine will produce more power as compared to a single one so because of these to effect we are going to take these two effects along with and the full set up performance will be analyzed.[1] observed that dual rotor will produce more power and will also produce more torque after a certain wind speed.[2] observed a $7 \%$ increase in $\mathrm{Cp}$ for a dual rotor wind turbine as compared to a single one.[3] observed that the coaxial dual rotor will produce more power. [4] observed that there is an $11-13 \%$ increase in power coefficient when a dual rotor is employed.[5] observed that a shrouded wind turbine will lead to a low cost per $\mathrm{kW}$.hr energy utilization as compared to an unshrouded one.[6] observed that power efficiency of $11.2 \%$ without diffuser of wind turbine while $13.5 \%$ with a shrouded wind turbine.[7]observed that with a long diffuser $(\mathrm{Lt}=1.47 \mathrm{D})$, there is an increase in the power output of approximately 4 to 5-times that of without diffuser wind turbine is achieved.[8] investigated .that means the increase in power generation is about $5 \%$ due to optimum flange angle as compared to bare one.[9] observed that a shrouded wind turbine produces more power as compared to a bare one.[10] observed that a flanged diffuser will enhance the performance of wind turbines.[11] observed that diffuser augmented wind turbine performs better.[12] diffuser-type wind turbine performs better.[13]rotor design aspects for diffuser augmented wind turbine.[14] observed that ducted or funnel-based wind turbine perform better as compared to bare one. In this paper, CFD analysis is performed on a single rotor, dual rotor, and ducted dual rotor wind turbine to analyze the parameter of toque and power produced.

\section{III . METHODOLOGY}

It has been observed experimentally in [1] that a dual rotor produces more torque and more rotational speed as compared to a single rotor wind turbine. Taking the same design consideration of wind turbine as given in[1],

Published By: Blue Eyes Intelligence Engineering DOI:10.35940/ijeat.D2500.0410421

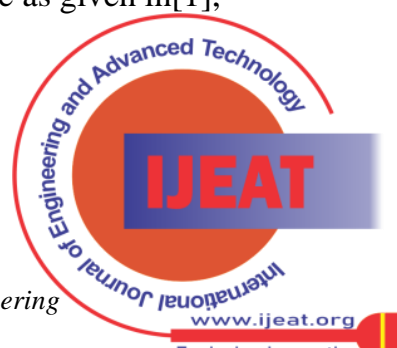


CATIA model was prepared for single rotor and dual rotor and dual ducted wind turbine rotor, then the analysis on ANSYS software is to conduct for a single, dual and dual ducted wind turbine as per given figure.

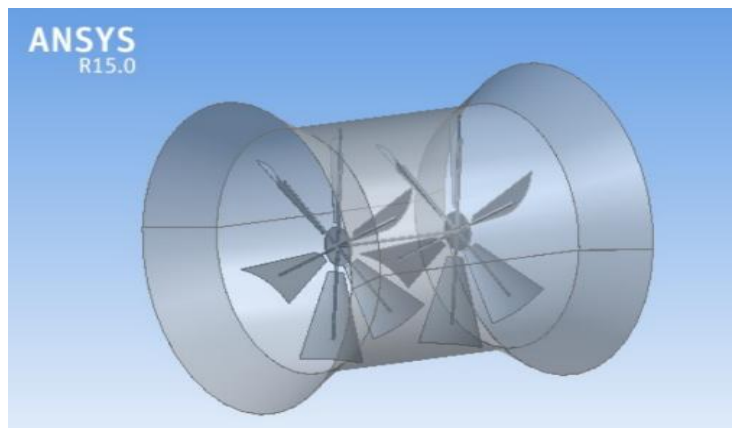

Figure 1(a)

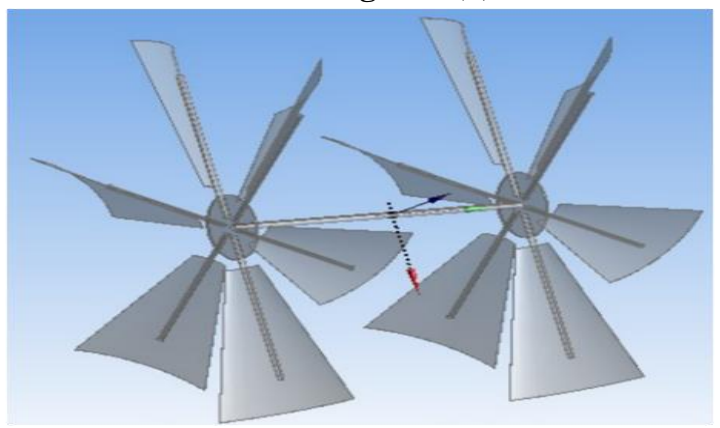

Figure 1 (b)

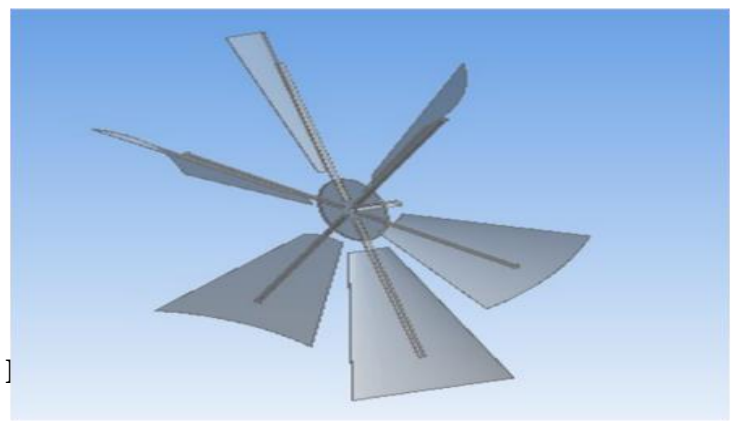

Figure 1 (c)

Figure 1 (a) Dual rotor 6+6 bladed ducted wind turbine. CATIA model.

(b) Dual rotor $6+6$ bladed wind turbine CATIA model.

(c) Single rotor 6 bladed CATIA model.

The designed model was prepared on CATIA software as per the given configuration in [1] wind turbine blade design was taken from [1]. Fig 1 represents the prepared CATIA model single, dual and ducted dual rotor model.

The fundamental equation used for wind turbine

$P=C p(0.5) * \rho * A * V 3$ where is power coefficient, $\rho=1.25$ $\mathrm{kg} / \mathrm{m} 3$ is air density, $(\mathrm{A}=1.813 \mathrm{~m} 2)$ wind turbine frontal area, $V$ is wind velocity, Diameter of dual rotor $=152 \mathrm{~cm}$.[1].the material of the blade is taken as aluminum with $6+6$ number of blades placed symmetrically.[1].based on above given reference no[1].model was prepared on CATIA for -

1. Single rotor 6 bladed wind turbine as per fig 1(c)

2. Dual rotor $6+6$ bladed wind turbine as per fig $1(\mathrm{~b})$

3. Dual ducted rotor $6+6$ bladed wind turbine as per fig 1(a).

\section{IV . RESULT AND ANALYSIS}

The analysis was conducted on ANSYS software for the above three segments of the wind turbine at different wind velocities and then results in terms of torque and power were observed as per the given table. It was already observed experimentally in [1] that a dual rotor $6+6$ bladed wind turbine produces more torque and power as compared to a single one. So here we are going to analyze the performance of single rotor, dual rotor, and dual ducted rotor on mechanical software ANSYS, and results are observed.

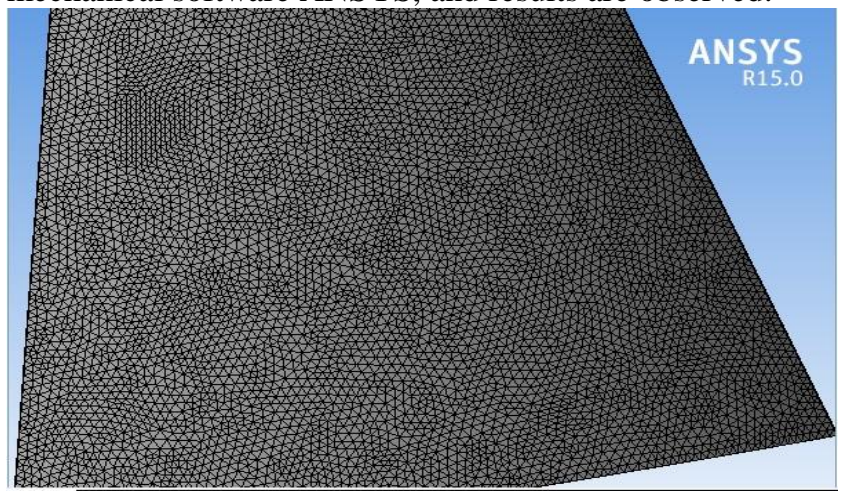

Figure 2(a)

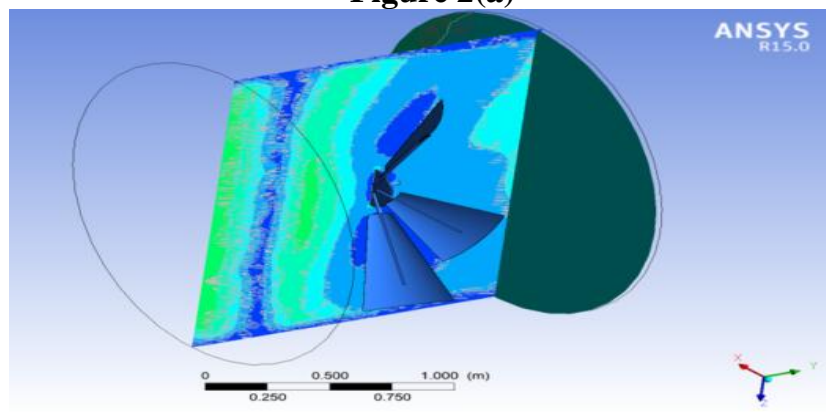

Figure 2 (b)

Figure 2 (a) Meshing CATIA model of the turbine blade. (b) Single rotor 6 bladed wind turbine torque analysis on ANSYS.

The above-given figure represents the meshing on ANSYS for single, dual, and ducted dual rotor wind turbine in 2 (a). And that of (b) represents the plane selecting of analysis on ANSYS for a single-rotor wind turbine.

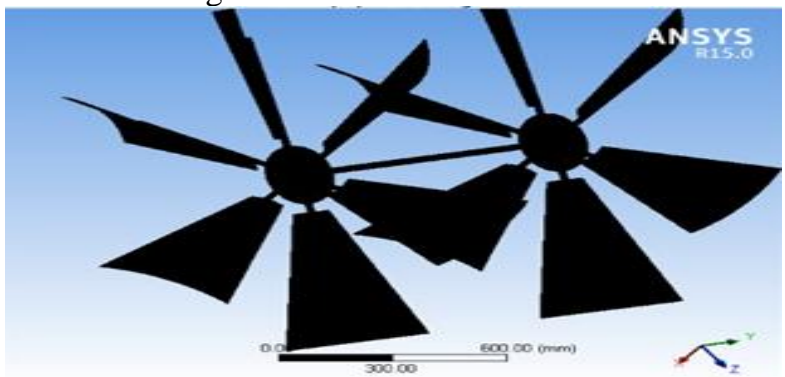

Figure 3(a)

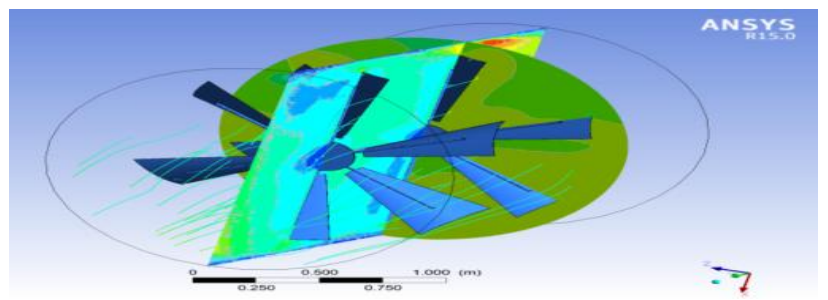

Figure 3 (b)

Published By:

Blue Eyes Intelligence Engineering \& Sciences Publication 
Figure 3(a) CATIA model of $6+6$ bladed dual rotor wind turbine. (b) CATIA model analysis on ANSYS.

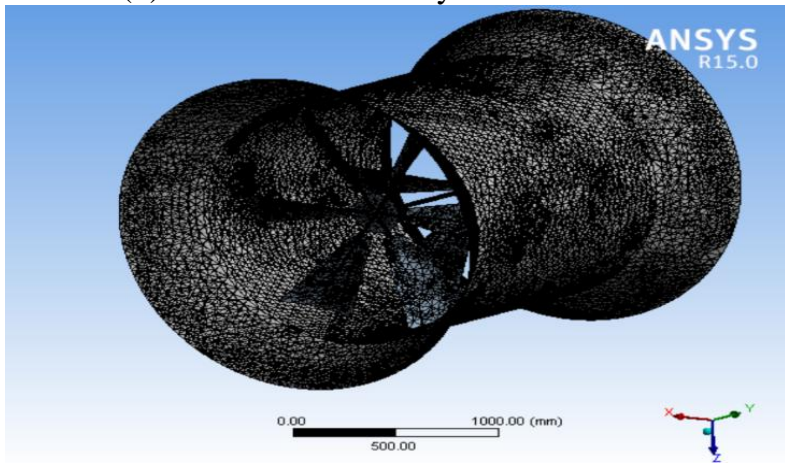

Figure 4 (a)

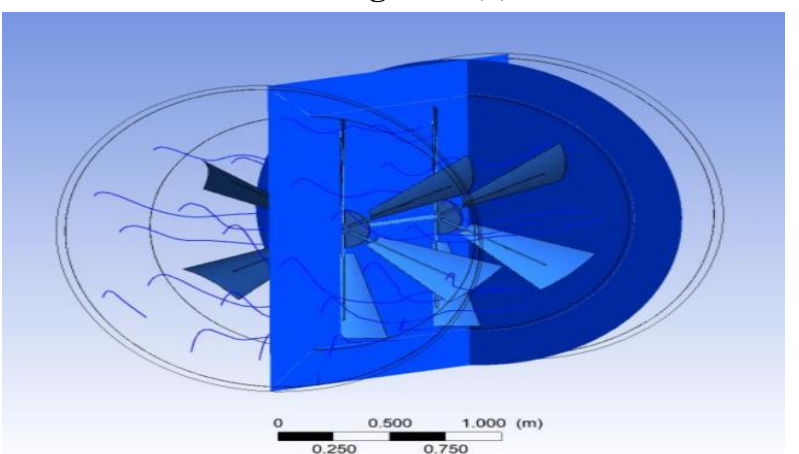

Figure 4 (b)

Figure 4 (a) represents the meshing of a dual ducted wind turbine on ANSYS and Figure 4(b) represents the analysis of dual ducted wind turbine on ANSYS. Results and analysis-analysis are carried out on ANSYS for the above given three segments on given velocities of wind which varies from 2 to $16 \mathrm{~m} / \mathrm{s}$ etc.

1.1 Analysis was carried out on ANSYS for a single rotor wind turbine as per the given designed parameters. The result was observed which shows the variation of rpm and tip speed ratio (TSR) concerning the given wind velocity.

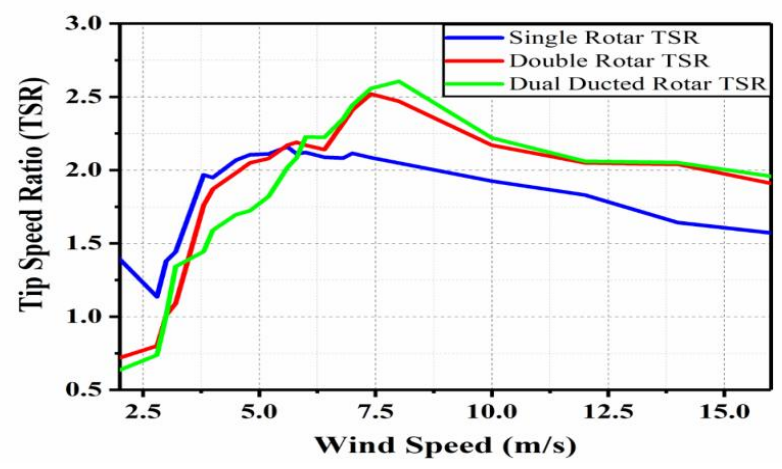

\section{Graph 1.1}

Explanation of graph 1.1- Graph 1.1 shows the variation of TSR for the single rotor, Dual rotor, and ducted dual rotor over common wind speed. the graph shows that at lower wind speed ducted dual rotor is having low TSR due to low rotor rpm but its TSR increases slightly after $5.8 \mathrm{~m} / \mathrm{s}$ of wind velocity as compared to the single rotor and dual rotor(without duct).

1.2 Analysis was carried out on ANSYS with different wind velocities; the braking load is calculated after the analysis of braking torque.

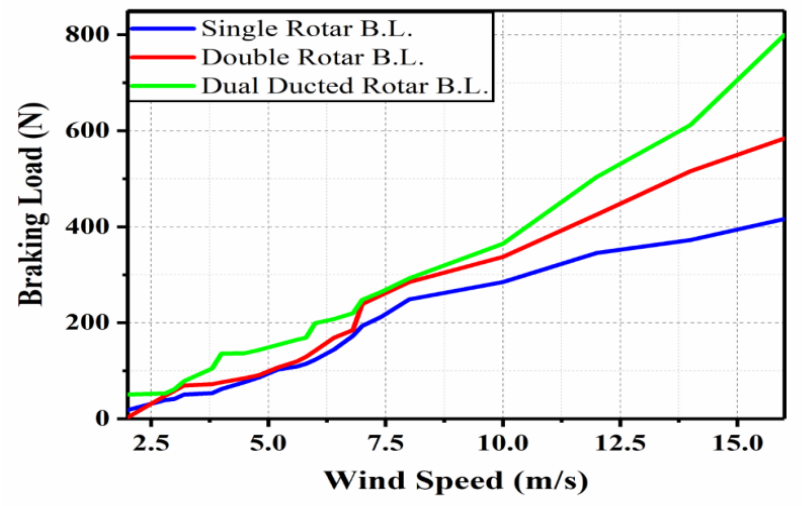

\section{Graph 1.2}

Explanation of graph 1.2-Graph 1.2 shows the variation of braking load for the single rotor, dual rotor and ducted dual rotor wind turbine over common wind speed the graph shows that the value of braking load is less for a single rotor wind turbine as compared to dual and ducted dual rotor wind turbine from beginning to the end of wind velocity. In which ducted dual rotor produces more braking load as compared to dual and single rotor wind turbine from the beginning $2 \mathrm{~m} / \mathrm{s}$ till the end of analysis means $16 \mathrm{~m} / \mathrm{s}$. The maximum value of braking load for a dual ducted wind turbine is $36.9 \%$ more than a dual rotor at $16 \mathrm{~m} / \mathrm{s}$ of wind velocity and $92.2 \%$ more than a single rotor at $16 \mathrm{~m} / \mathrm{s}$ of wind velocity.

1.3 Analysis was carried out on ANSYS for the single rotor, dual rotor, and ducted dual-rotor, and torque was observed with different wind velocities.

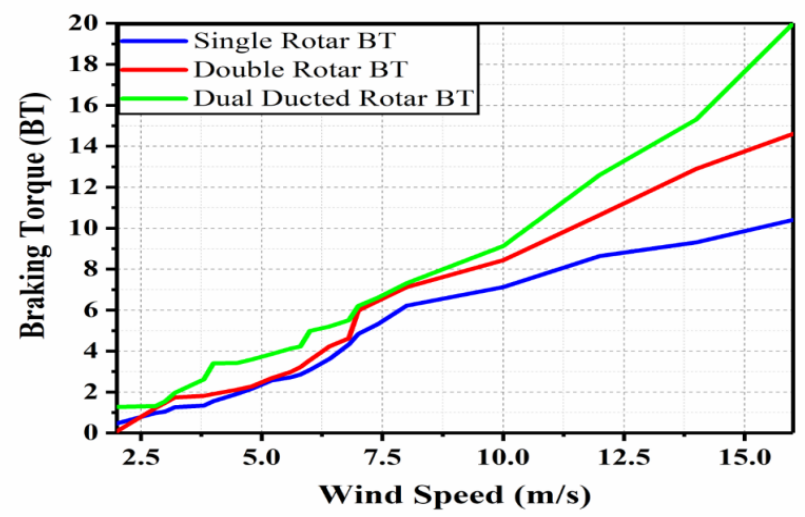

\section{Graph 1.3}

Explanation of graph 1.3- Graph 1.3 shows that the torque produced by the single rotor is less as compared to dual and ducted dual rotor wind turbine moreover ducted dual rotor produces more torque as compared to both single and dual rotor wind turbine over common wind velocity analysis. The maximum value of torque for a dual ducted wind turbine is $36.9 \%$ more than a dual rotor at $16 \mathrm{~m} / \mathrm{s}$ of wind velocity and $92.2 \%$ more than a single rotor at $16 \mathrm{~m} / \mathrm{s}$ of wind velocity. 1.4 Analysis was carried out on ANSYS for the single rotor, dual rotor, and ducted dual-rotor, and power was observed with different wind velocities.

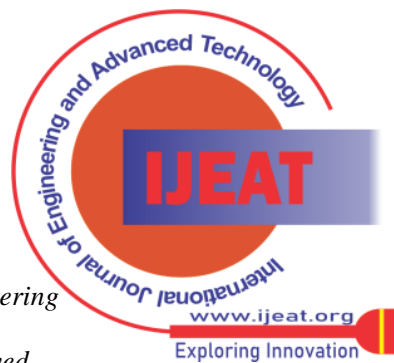




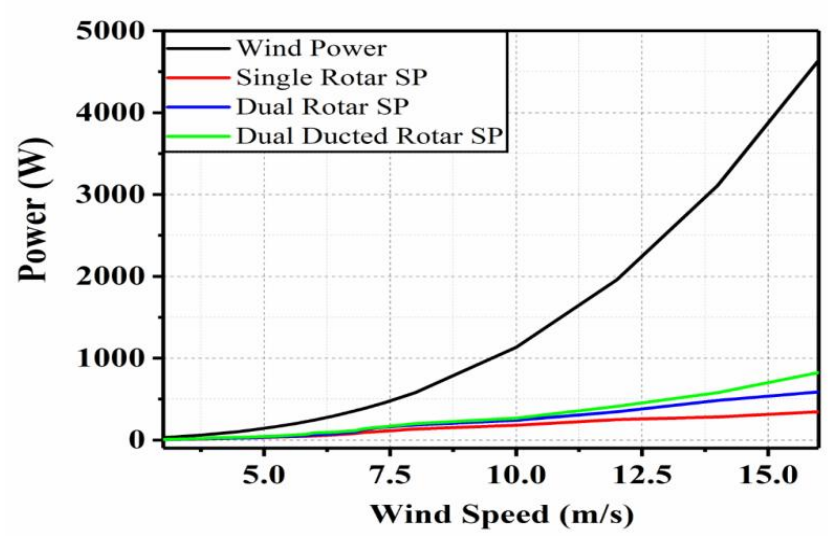

\section{Graph 1.4}

Explanation of graph 1.4- Graph 1.4 shows that the initial condition of wind velocity analysis single rotor produces more power but after $3 \mathrm{~m} / \mathrm{s}$ of wind velocity dual rotor produces more power but as the wind velocity increases beyond $3 \mathrm{~m} / \mathrm{s}$ ducted dual rotor produces more power as compared to both single and dual rotor wind turbine. The maximum value of the power produced for a dual ducted wind turbine is $40.48 \%$ more than a dual rotor at $16 \mathrm{~m} / \mathrm{s}$ of wind velocity and $139.66 \%$ more than a single rotor at $16 \mathrm{~m} / \mathrm{s}$ of wind velocity. At this velocity, the max power produced for a ducted dual rotor wind turbine is $17.76 \%$ of wind power produced at this velocity.

1.5 Analysis was carried out on ANSYS for the single rotor, dual rotor, and ducted dual-rotor, and power coefficient was observed with different wind velocities.

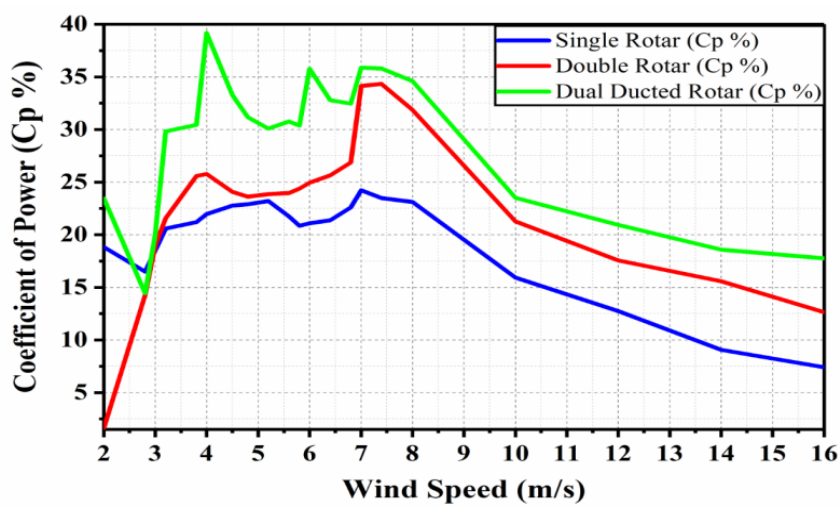

\section{Graph 1.5}

Explanation of graph 1.5-Graph represents the variation of coefficient of power for single, dual, and ducted dual rotor wind turbine over common wind velocity. The graph shows that at $2 \mathrm{~m} / \mathrm{s}$ initially ducted dual rotor wind turbine is having a larger value of coefficient it decreases afterward for an instant but it is having a larger value of power coefficient afterward thorough the analysis as compared to single rotor and dual rotor wind turbine. The maximum value of the power coefficient for a dual ducted wind turbine is $14.06 \%$ more than a dual rotor and $61.63 \%$ more than a single rotor.

\section{CONCLUSION}

An analysis was performed on software ANSYS for which results are compared for various wind speeds for the single rotor, dual rotor, and dual ducted rotor. It is concluded that the torque produced by the single rotor is less as compared to dual and ducted dual rotor wind turbine moreover ducted dual rotor produces more torque as compared to both single and dual rotor wind turbine over common wind velocity analysis. The maximum value of torque for a dual ducted wind turbine is $36.9 \%$ more than a dual rotor at $16 \mathrm{~m} / \mathrm{s}$ of wind velocity and $92.2 \%$ more than a single rotor at $16 \mathrm{~m} / \mathrm{s}$ of wind velocity. If we conclude in terms of power production then I will conclude that the maximum value of the power produced for a dual ducted wind turbine is $40.48 \%$ more than a dual rotor at $16 \mathrm{~m} / \mathrm{s}$ of wind velocity and $139.66 \%$ more than a single rotor at $16 \mathrm{~m} / \mathrm{s}$ of wind velocity. At this velocity, the max power produced for a ducted dual rotor wind turbine is $17.76 \%$ of wind power produced at this velocity. So I can say finally that dual ducted rotor performs well as compared to bare dual and single rotor wind turbine in terms of torque and power produced.

\section{ACKNOWLEDGMENT}

We acknowledge the support from Dr.Arun Kumar Tiwari, Head of Department of Mechanical Engineering, Institute of Engineering and Technology, Sitapur Road Lucknow.

\section{REFERENCES}

1. Vinay Mishra, Dr.H.K.Paliwal(2019) 'Experimented Examination of Power Produced for Dual Rotor Wind Turbine over Single Rotor Wind Turbine 'International Journal of Innovative Technology and Exploring Engineering (IJITEE) ISSN: 2278-3075, Volume-9 Issue-2.

2. A Rosenberg, S Selvaraj, and A Sharma ,( 2014.)'A Novel Dual-Rotor Turbine for Increased Wind Energy Capture 'Department of Aerospace Engineering, Iowa State University, Ames, Iowa, 50011, USA, Article in Journal of Physics Conference Series.

3. Milind Deotale, Abhishek Chavan, Abhishek Patil, Bhavesh Patil (2018 )‘Co-Axial Rotor Wind Turbine'IJARSE ISSN 2319-8354, VOL 7 Issue 4.

4. Michal Lipian, Ivan Dobrev, Maciej Karczewski, Fawaz Massouh, Krzysztof Jozwik,( 2019 )'Small wind turbine augmentation: Experimental investigations of shrouded- and twin-rotor wind turbine systems' Energy.

5. Peter E. Jenkins, Abdalfadel Younis, Yuxuan Chen, (2017) Design and Analysis of a Dual Rotor Turbine with a Shroud Using Flow Simulations, Journal of Power and Energy Engineering, ISSN Online: 2327-5901, 5, 25-40.

6. Riyantoa, Nugroho Agung Pambudia,*, Rusdi Febriyantoa,( 2018) The Performance of Shrouded Wind Turbine at Low Wind Speed Condition, 10th International Conference on Applied Energy (ICAE2018), Hong Kong, China.

7. Yuji Ohya * and Takashi Karasudani, (2010) A Shrouded Wind Turbine Generating High Output Power with Wind-lens Technology, 3, 634-649; energies ISSN 1996-1073 www.mdpi.com/journal/energies. Energies.

8. Aly M. El-Zahaby, A.E. Kabeel *, S.S. Elsayed, M.F. Obiaa,( 2016) CFD analysis of flow fields for shrouded wind turbine's diffuser model with different flange angles, Alexandria Engineering Journal 2017 (56) 171-179.

9. K. Abea, M. Nishidab, A. Sakuraia, Y. Ohyac, H. Kiharaa, E. Wadad, K. Satod, (2005) Experimental and numerical investigations of flow fields behind a small wind turbine with a flanged diffuser, Journal of Wind Engineering and Industrial Aerodynamics 93 (2005) 951-970.

10. Ken-ichi Abea,*, Yuji Ohyab,( 2004.) An investigation of flow fields around flanged diffusers using CFD, Journal of Wind Engineering and Industrial Aerodynamics 92 (2004) 315-330.

11. Arouge Agha, Hassam Nasarullah Chaudhry1 (2018), Fan Wang, Diffuser Augmented Wind Turbine (DAWT) Technologies: A Review, International Journal of Renewable Energy Research A.Agha et al., Vol.8, No.3.

12. Grady M. Isensee1, Hayder Abdul-Razzak, (2012.) Modeling and Analysis of Diffuser Augmented Wind Turbine, International Journal of Energy Science, IJES Vol.2 Iss.3 2012 www .ijesci.org. PP.84-88

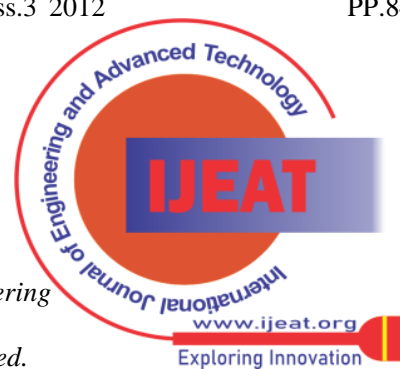

Blue Eyes Intelligence Engineering \& Sciences Publication (C) Copyright: All rights reserved. 
13. Søren Hjort * and Helgi Larsen, (2015)Rotor Design for Diffuser Augmented Wind Turbines, Energies 2015, 8, 10736-10774; doi:10.3390/en81010736.

14. Nallapaneni Manoj Kumara,*, M. S. P Subathrab, Orville Damaso Cotaa, (2015) Design and Wind Tunnel Testing of Funnel Based Wind Energy Harvesting System, Procedia Technology 2133 - 40.

\section{AUTHORS PROFILE}

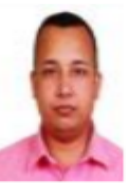

Vinay Mishra, working as an Asst professor in BNCET, Lucknow Uttar Pradesh India, is having more than 12 years of teaching experiences along with Govt of India defence industrial experience, he published many papers in national and international journals , he had completed his engineering in mechanical branch from UPTU in 2006, he is an active lifetime member of ISTE i.e. Indian Society for Technical education. He worked on many defence Govt projects like Su 30, LCA (Light Combat Aircraft) etc. He had gone thru various training program under Govt of India, ministry of defence. He is well known for his teaching ability in relevant areas. He is pursuing his Ph.D. from AKTU Lucknow, his main research field are thermal engineering, turbo machinery and renewable energy resources.

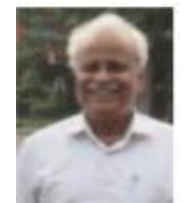

Dr H.K. Paliwal, working as a Ex Director \& professor at Institute of Engineering \& Technology , Sitapur road, Lucknow Uttar Pradesh ,India, he is having more than 27 years of teaching experience he had completed his $\mathrm{PhD}$ from IIT Kanpur in the field of thermal engineering ,from the last 20 years he published many papers in reputed journals at national and international level, his field of specialization is thermal engineering, he is an active member of various national and international Societies in the field of research. He is also working as a panel expert and active member of research committee at graduate ,post graduate and $\mathrm{PhD}$ level.

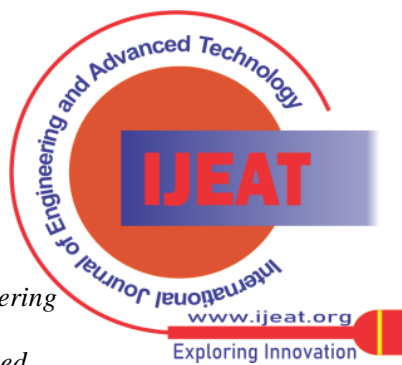

